\title{
Analisis Karakteristik Sistem Kontrol Temperatur Berbasis Autonics TK4S-14RN Untuk Prototipe Pengering Bahan Pakaian
}

\author{
Desi Silvia Astuti ${ }^{1}$, Ahmad Aminudin ${ }^{1}$, Waslaluddin ${ }^{2}$ \\ ${ }^{1}$ Program Studi Fisika, Universitas Pendidikan Indonesia, Jl. Dr. Setiabudhi 229 \\ Bandung 40154, Indonesia \\ ${ }^{2}$ Laboratorium Fisika Instrumentasi, Universitas Pendidikan Indonesia, Jl. Dr. \\ Setiabudhi 229 Bandung 40154, Indonesia
}

* Penulis Penanggungjawab. E-mail: : desi.silvia.astuti@gmail.com (Desi Silvia Astuti), Telp: $+62-89-87003179$

\begin{abstract}
ABSTRAK
Telah dilakukan analisis karakteristik sistem kontrol temperatur pada prototipe pengering bahan pakaian berbasis Autonics TK4S-14RN. Sistem kendali atau kontrol merupakan sistem pengontrolan suatu proses yang bertujuan untuk memperoleh suatu variabel pada nilai tertentu. Sistem kontrol loop tertutup merupakan sistem kontrol yang digunakan pada penelitian ini yang terdiri dari elemen implementasi kontrol berupa tipe kontrol on/off pada sistem heater dari rangkaian lampu berdaya 100 watt standard bulb dengan $\mathrm{T}_{\text {maks }}=40,4{ }^{\circ} \mathrm{C}$ dan pada sistem cooler dari rangkaian kipas $12 \mathrm{VDC}$ dengan $\mathrm{V}_{\mathrm{in}}=10 \mathrm{VDC}$. Elemen koreksi berupa prosedur pemrogaman Autonics TK4S-14RN sebagai perangkat lunak. Elemen pengukuran menggunakan rangkaian sensor RTD PT100 dengan sensitivitas $0,3931 \Omega /{ }^{\circ} \mathrm{C}$, ketidakakuratan $\pm 0,000673$, presentase kesalahan presisi dan akurasi yaitu $0,17 \%$ dan 1,9\%. Karakterisasi Autonics TK4S-14RN sebagai kontrol temperatur dilakukan untuk meninjau tanggapan respon transien dan tunak. Hasil pengujian diperoleh sistem berisolasi dengan simpangan sebesar $0,1^{\circ} \mathrm{C}$, sehingga sistem steady state sebesar $0,28 \%$ terhadap $\mathrm{SV}$, dengan $\mathrm{t}_{\mathrm{s}}=140$ $268 \mathrm{~s}$ dan $\mathrm{M}_{\mathrm{p}}=0,85-1,42 \%$. Dari hasil penelitian ini sistem kontrol yang dibuat dapat dijadikan sebagai basis kendali temperatur pada prototipe pengering bahan pakaian.
\end{abstract}

Keywords: Sistem Kontrol Loop Tertutup; Kendali Temperatur; Autonics TK4S14RN; Prototipe Pengering Bahan Pakaian; Karakteristik Sistem 


\section{ABSTRACT}

Has been done characteristic analysis of temperature control system for clothes dryer prototype based on Autonics TK4S-14RN. Control system of a process which aims to obtain a variable at a certain value. Closed loop control system as type control system was used on this research consisting of control implementation elements is the type of control on/off on the heater system from a standard 100 watt power bulb circuit with $\mathrm{T}_{\text {maks }}=40,4^{\circ} \mathrm{C}$ and on the cooler system from the $12 \mathrm{VDC}$ fan circuit with $\mathrm{V}_{\mathrm{in}}=10 \mathrm{VDC}$. Elements of correction from Autonics program TK4S-14RN as the software. Measurement elements using RTD PT100 sensor set with a sensitivity of $0,3931 \Omega /{ }^{\circ} \mathrm{C}$, innaccuracies $\pm 0,000673$, the precision of error and accuracy $0,17 \%$ dan 1,9\%. Characterization of Autonics TK4S-14RN as a temperature control was carried out to review the response of the transient and steady state. Then the result obtained the system isolated with a $0,1^{\circ} \mathrm{C}$, which steady state is $0,28 \%$ against $\mathrm{SV}$, with $\mathrm{t}_{\mathrm{s}}=140-268 \mathrm{~s}$ and $\mathrm{M}_{\mathrm{p}}=0,85$ $1,42 \%$. From the result of this research, control system can be served as temperature base control for clothes dryer prototype.

Keywords: Sistem Kontrol Loop Tertutup; Kendali Temperatur; Autonics TK4S14RN; Prototipe Pengering Bahan Pakaian; Karakteristik Sistem

\section{Pendahuluan}

Pada pengeringan bahan pakaian terjadi perpindahan panas dari lingkungan ke bahan dan terdapat proses penguapan fluida [1]. Tujuan dari proses pengeringan adalah untuk menghilangkan kandungan air pada suatu bahan [2]. Berdasarkan hal tersebut pengeringan merupakan proses pengurangan kandungan air dengan penguapan. Metode pengeringan terbagi menjadi dua, yang pertama adalah cara alami yaitu dengan memanfaatkan panas sinar matahari dan yang kedua dengan pengeringan buatan dengan mesin pengering di mana kelembaban, temperatur, kecepatan udara, dan waktu dapat diatur dan diawasi [3]. Adapun, menaikkan temperatur merupakan salah satu alternatif untuk mempercepat proses pengeringan pada mesin pengering pakaian [4].

Mesin pengering pakaian telah mengalami pergeseran dari sistem manual ke sistem otomatis. Pada 
penelitian sebelumnya telah dibuat sebuah rancang bangun sistem kontrol lemari pengering pakaian berbasis mikrokontroler Atmega8535 [5]. Sistem kontrol yang dibuat untuk mengendalikan besar temperatur dan kelembaban yang diukur dengan rangkaian sensor SHT11. Selain itu terdapat rangkaian power supply, LCD, pemanas, pendingin, serta diprogram dengan BASCOM (Basic Compller) pada sistem kontrol yang dibuat. Sistem kontrol merupakan suatu perangkat yang dapat mengatur, memerintah, mengarahkan, atau mengatur perilaku perangkat atau sistem lain [6]. Nama lain dari sistem kontrol adalah sistem pengaturan atau sistem pengendalian [7]. Pada penelitian tersebut merupakan sistem kontrol loop tertutup dengan prinsip konveksi paksa [5]. Sistem kontrol loop tertutup merupakan sistem kontrol yang sinyal keluarannya mempunyai pengaruh langsung pada aksi pengontrolan [8].

Selain mikrokontroler, terdapat Progammable Logic Controller (PLC) yaitu sebuah komputer yang khusus dirancang untuk mengontrol suatu proses, dapat berupa sistem servo dan kontrol on/off [9]. Variabel yang dikontrol dalam penelitian ini adalah temperatur. Selain mikrokontroler dan PLC, terdapat jenis kontroler lain yang didesain khusus untuk mengontrol suatu proses tertentu. Salah satunya adalah Autonics TK4S-14RN yang merupakan temperature controller. Autonics TK4S-14RN didesain memiliki sistem pengukur temperatur menggunakan sensor, sistem pemanas, sistem pendingin, power supply, multi SV setting, dan sistem penampil digital yang terintegrasi menjadi satu unit yang kompak. Sistem kontrol yang ada dapat bekerja secara maksimal dan dikehendaki oleh pengguna dengan mengatur parameter-parameter yang dibutuhkan dengan akurasi $\pm 0,3 \%$. Sistem kontrol pada Autonics TK4S14RN diantaranya PID (Proporsional, Integral, dan Defrensial) dan on/off ${ }^{[10]}$.

Pada penelitian ini dilakukan pembuatan serta analisis karakteristik sistem dari sistem kontrol temperatur yang berbasis Autonics TK4S-14RN. Temperature controller tersebut dirangkai dengan rangkaian sensor RTD PT100 sebagai elemen pengukuran, rangkaian lampu 100 watt standard bulb sebagai elemen heater, dan rangkaian kipas 12VDC sebagai elemen cooler. Rangkaian tersebut 
dihubungkan dengan pin-pin pada Auotnics. Rangkaian sistem kontrol tersebut diletakkan pada sebuah chamber sebagai prototipe pengering bahan pakaian yang dibuat tertutup dengan dilapisi fiber. Kemudian dilakukan pengujian terhadap sistem kontrol yang dibuat untuk mengetahui karakteristik sistem. Karakteristik sistem tersebut diidentifikasi dengan menganalisis tanggapan respon keadaan transien dan keadaan tunak dalam sebuah grafik yang didapatkan dari pengambilan data temperatur dan kondisi sistem terhadap perubahan waktu [11].

\section{Bahan dan Metode}

Penelitian dilakukan dengan metode eksperimen. Metode eksperimen yang dilakukan diawali dengan melakukan perancangan chamber untuk ruangan prototipe, kemudian perancangan rangkaian sistem kontrol, setelah itu tahap pengujian. Pengujian ini dilakukan untuk mengidentifikasi karakteristik sistem pada sistem kontrol temperatur berbasis Autonics TK4S14RN. Pengujian dilakukan dengan mengatur satu nilai temperatur yang diinginkan (SV) dengan variasi temperatur awal yang berbeda. Skematik dari rancangan sistem kontrol ditunjukkan pada Gambar 1.

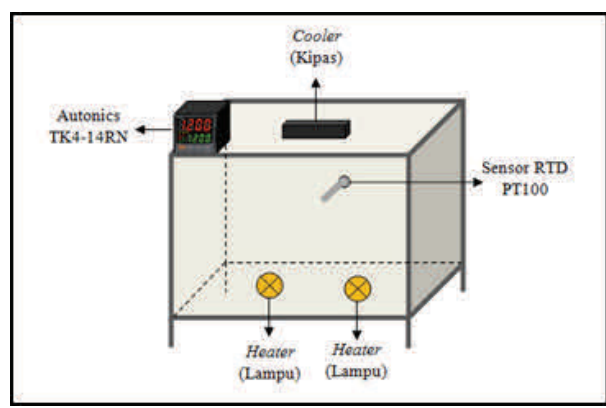

Gambar 1. Skema Sistem Kontrol Temperatur berbasis Autonics TK4S-14RN

\subsection{Pengujian Respon Autonics TK4S $-14 R N$}

Sistem kontrol yang dibuat merupakan sistem kontrol loop tertutup pada sebuah chamber tertutup fiber dengan dimensi ukuran $0,5 \mathrm{~m}$ x $0,4 \mathrm{~m} \times 0,43 \mathrm{~m}$ yang terdiri dari elemen pengukuran temperatur yaitu rangkaian sensor RTD PT100 dengan sensitivitas respon $0,3931 \Omega /{ }^{\circ} \mathrm{C}$, ketidakakuratan $\pm 0,000673$, presentase kesalahan presisi sebesar $0,17 \%$, dan presentase kesalahan akurasi sebesar $1,9 \%$, kemudian terdapat elemen implementasi kontrol berupa tipe kontrol on/off pada sistem heater (pemanas) dari rangkaian lampu berdaya 100 watt jenis standard 
bulb dengan temperatur maksimal yang dihasilkan dalam prototipe sebesar $40,4^{\circ} \mathrm{C}$ dan pada sistem cooler (pendingin) dari rangkaian kipas $12 \mathrm{VDC}$, kemudian terdapat elemen koreksi berupa prosedur pemrogaman Autonics TK4S-14RN yang merupakan perangkat lunak. Elemen-elemen tersebut diintegrasikan pada Autonics TK4S-14RN dengan rangkaian yang ditunjukkan pada Gambar 2.

Prinsip kerja dari sistem ini membaca nilai temperatur pada sensor kemudian membandingkan nilai temperatur yang terukur (PV) dan nilai temperatur yang diinginkan (SV). Ketika terdapat perbedaan, saklar output atau alarm pada Autonics TK4S -14RN akan aktif untuk mengontrol temperatur ruangan dan ketika $\mathrm{PV}=\mathrm{SV}$ maka output atau alarm dalam keadaan off.

Pengujian dilakukan dengan nilai temperatur yang diinginkan (SV) pada temperatur $35^{\circ} \mathrm{C}$ dengan variasi temperatur awal yang berbeda yaitu $30^{\circ} \mathrm{C}, \quad 31^{\circ} \mathrm{C}, \quad 32^{\circ} \mathrm{C}, \quad 33^{\circ} \mathrm{C}$, dan $34^{\circ} \mathrm{C}$. Pengambilan data dilakukan pada masing-masing satu nilai SV dan satu temperatur awal selama $\mathrm{t}=480$ sekon, sehingga didapatkan masing-masing pengujian sebanyak lima buah grafik tanggapan sinyal hubungan temperatur terhadap waktu. Proses pengambilan data ditunjukkan pada Gambar 3.

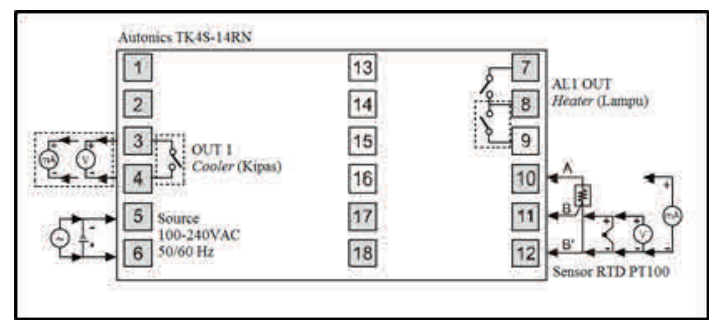

Gambar 2. Skematik rangkaian kendali temperatur berbasis Autonics TK4S-14RN

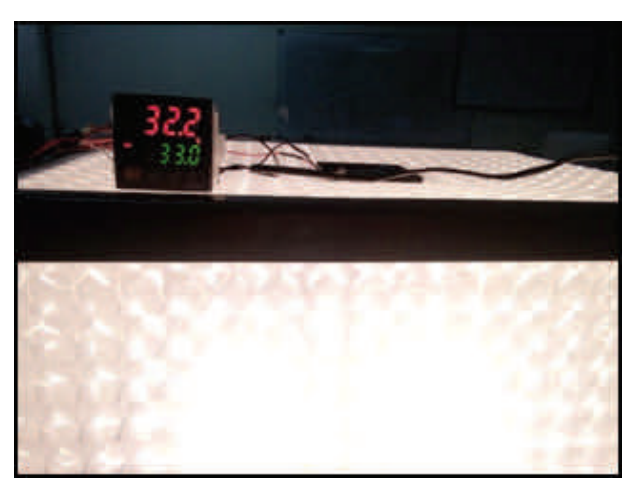

Gambar 3. Pengambilan data karakterisasi Autonics TK4S$14 \mathrm{RN}$

\section{Hasil dan Pembahasan}

Hasil pengujian dengan nilai SV $35^{\circ} \mathrm{C}$ dengan lima nilai temperatur awal beragam diantaranya $30^{\circ} \mathrm{C}, 31^{\circ} \mathrm{C}$, $32^{\circ} \mathrm{C}, 33^{\circ} \mathrm{C}$, dan $34^{\circ} \mathrm{C}$. ditunjukkan pada gambar 4. Pada grafik Gambar 4 sumbu x merupakan waktu dan sumbu y merupakan temperatur. Berdasarkan grafik tanggapan sinyal hubungan temperatur terhadap waktu bahwa kurva bukan merupakan fungsi eksponensial (sistem orde satu), atau mengalami overshoot yang turun menuju keadaan tunak (sistem orde tinggi). 


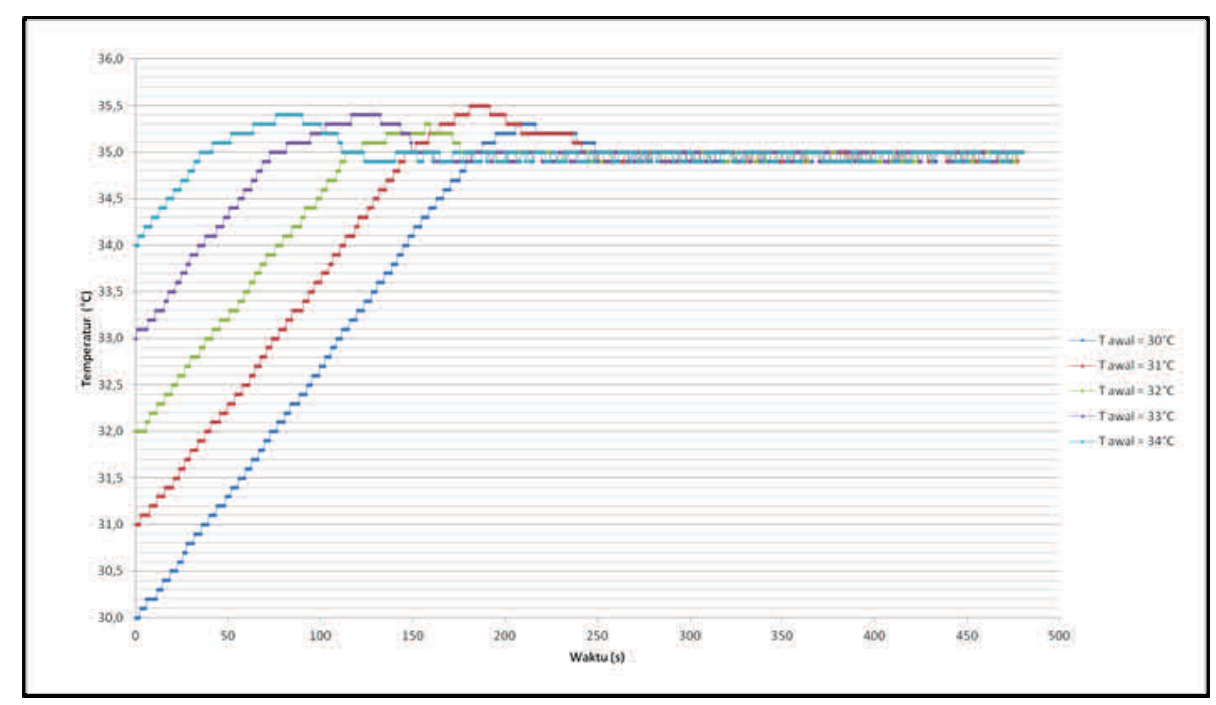

Gambar 4. Grafik hubungan temperatur terhadap waktu

Kurva mengalami osilasi teredam sebelum mencapai keadaan tunak atau termasuk jenis sistem orde dua. Grafik yang diperoleh dari pengambilan data tersebut berosilasi dan memiliki tanggapan underdamped dengan nilai $\zeta: 0<\zeta<1$. Grafik tersebut dilakukan analisis karakteristik sistem dengan mengetahui dua tanggapan waktu dari sebuah sistem kontrol yaitu tanggapan transien (transient response) dan tanggapan keadaan tunak (steady state response). Tanggapan transien dari grafik di atas dimulai dari tanggapan awal hingga awal tanggapan sistem mencapai nilai akhir yang diinginkan (final state). Berdasarkan Gambar 4 didapatkan spesifikasi tanggapan transien yang ditunjukkan pada Tabel 1.
Sedangkan, tanggapan keadaan tunak dimulai pada saat tanggapan mulai pertama kali mendekati nilai akhir hingga waktu yang tak terhingga. Dalam hal ini waktu dibatasi hingga 480 sekon (8 menit). Kegunaan dari tanggapan transien adalah untuk menganalisa sifat naik atau permulaan dari suatu sistem, serta tanggapan keadaan tunak yaitu untuk menganalisa karakteristik sistem pada saat mencapai harga akhir. Pada grafik di atas, juga diperoleh bahwa temperatur berisolasi pada rentang temperatur $34,9^{\circ} \mathrm{C}$ dan $35^{\circ} \mathrm{C}$. Suatu nilai keluaran dikatakan berada pada keadaan setimbang atau steady state apabila keluaran tersebut mempunyai nilai toleransi sebesar 5\% atau $2 \%$ (toleransi pabrik) dari nilai keluarannya. 
Tabel 1. Spesifikasi tanggapan transien

\begin{tabular}{lccccc}
\hline $\begin{array}{r}\text { Spesifikasi } \\
\text { Tanggapan }\end{array}$ & $\mathrm{T}_{0}=30^{\circ} \mathrm{C}$ & $\mathrm{T}_{0}=31^{\circ} \mathrm{C}$ & $\mathrm{T}_{0}=32^{\circ} \mathrm{C}$ & $\mathrm{T}_{0}=33^{\circ} \mathrm{C}$ & $\mathrm{T}_{0}=34^{\circ} \mathrm{C}$ \\
\hline delay time $\left(\mathrm{t}_{\mathrm{d}}\right)$ & $92 \mathrm{~s}$ & $74 \mathrm{~s}$ & $59 \mathrm{~s}$ & $34 \mathrm{~s}$ & $17 \mathrm{~s}$ \\
rise time $\left(\mathrm{t}_{\mathrm{r}}\right)$ & $182 \mathrm{~s}$ & $146 \mathrm{~s}$ & $114 \mathrm{~s}$ & $72 \mathrm{~s}$ & $35 \mathrm{~s}$ \\
peak time $\left(\mathrm{t}_{\mathrm{p}}\right)$ & $206 \mathrm{~s}$ & $181 \mathrm{~s}$ & $157 \mathrm{~s}$ & $117 \mathrm{~s}$ & $75 \mathrm{~s}$ \\
$\begin{array}{l}\text { maximum } \\
\text { overshoot }\left(\mathrm{M}_{\mathrm{p}}\right)\end{array}$ & $0,85 \%$ & $1,42 \%$ & $0,85 \%$ & $1,14 \%$ & $1,14 \%$ \\
settling time $\left(\mathrm{t}_{\mathrm{s}}\right)$ & $268 \mathrm{~s}$ & $249 \mathrm{~s}$ & $205 \mathrm{~s}$ & $179 \mathrm{~s}$ & $140 \mathrm{~s}$ \\
\hline
\end{tabular}

Pada grafik tersebut didapatkan nilai simpangan masing-masing adalah sebesar 0,1 sehingga diperoleh nilai toleransi sebesar 0,28\%. Dengan demikian, pada pengujian ini sistem telah mencapai keadaan setimbang atau steady state. Semakin besar perbedaan temperatur awal dengan temperatur yang diinginkan, maka waktu yang diperlukan untuk mencapai nilai SV semakin besar. Hal ini juga berbanding lurus dengan waktu terjadinya overshoot, semakin lama waktu untuk mencapai SV maka waktu overshoot pun akan semakin lama. Hal ini dikarenakan oleh elemen heater pada alarm1 akan semakin panas sehingga temperaturnya akan semakin tinggi. Hal ini menyebabkan pemanasan di dalam ruangan akan terus terjadi walaupun lampu sudah tidak menyala. Pemanasan pada ruangan akan berhenti ketika terjadi kesetimbangan termal di dalam ruangan akibat adanya udara dari elemen cooler. Pada saat kesetimbangan termal tercapai, kipas akan terus aktif sebagai pendingin hingga temperatur ruangan yang terukur oleh sensor sama dengan nilai SV pada Autonics.

Berdasarkan analisis tanggapan transien dan keadaan tunak yang telah dilakukan didapatkan karakteristik keadaan tunak yang baik sehingga rangkaian sistem kendali temperatur yang berbasis Autonics TK4S-14RN dapat digunakan dalam prototipe pengering bahan pakaian. Oleh karena itu sistem kendali temperatur dalam prototipe pengering bahan pakaian dapat mengkondisikan besar temperatur di sekitar nilai SV. 


\section{Simpulan}

Karakteristik dari sistem kontrol temperatur Autonics TK4S-14RN untuk prototipe pengering bahan pakaian terdiri dari dua karakteristik tanggapan respon, yaitu tanggapan respon transien dan tanggapan respon tunak. Pada pengujian dengan nilai SV $35^{\circ} \mathrm{C}$ dan lima nilai temperatur awal diantaranya $30^{\circ} \mathrm{C}, 31^{\circ} \mathrm{C}, 32^{\circ} \mathrm{C}$, $33^{\circ} \mathrm{C}$, dan $34^{\circ} \mathrm{C}$ didapatkan tanggapan respon transien berupa $t_{d}=17 \mathrm{~s}-92$ $\mathrm{s}, \mathrm{t}_{\mathrm{r}}=35 \mathrm{~s}-182 \mathrm{~s}, \mathrm{t}_{\mathrm{p}}=75 \mathrm{~s}-206 \mathrm{~s}$, $\mathrm{M}_{\mathrm{p}}=0,85 \%-1,42 \%$, dan $\mathrm{t}_{\mathrm{s}}=140 \mathrm{~s}-$ 268 s. Respon keadaan tunak berisolasi dengan simpangan sebesar $0,1^{\circ} \mathrm{C}, \quad$ sehingga sistem kontrol temperatur pada prototipe pengering bahan pakaian berbasis Autonics TK4S-14RN memiliki nilai keadaan tunak sebesar $0,28 \%$ dengan rentang waktu untuk mencapai keadaan tunak adalah $\mathrm{t}=140-268 \mathrm{~s}$.

\section{Referensi}

1. Nainggolan, R. (2014). Rancang Bangun Kondesor Untuk Mesin Pengering Pakaian Sistem Pompa Kalor Dengan Daya 1PK.

2. Salli, G. J., \& Fat, J. (2015). PERANCANGAN DAN REALISASI SISTEM PENGERING BUAH APEL
MENGGUNAKAN

LAMPU

INFRAMERAH.

Jurnal Kajian

Teknologi, 11(1).

3. Arora, R. C. (2012). Refrigeration and air conditioning. PHI Learning Pvt. Ltd..

4. ZACHARIACE NUGRAHA, A. L. B. E. R. T., Warsito, A., \& Syakur, A. (2011). PERANCANGAN MODUL INVERTER FREKUENSI TINGGI SEBAGAI PEMANAS INDUKSI UNTUK APLIKASI PENGERING PAKAIAN (Doctoral dissertation, University Diponegoro).

5. Fauren, R., Jaya, P., \& Budayawan, K. (2018). RANCANG BANGUN SISTEM KONTROL LEMARI PENGERING PAKAIAN BERBASIS MIKROKONTROLER ATMEGA8535. Jurnal Vokasional Teknik Elektronika dan Informatika, 4 (1).

6. Eltaieb, A. A., \& Min, Z. J. (2013). Automatic Water Level Control System. International Journal of Science and Research (IJSR), 15051509.

7. Sulasno \& Prayitno, T. A. (2006). Teknik Sistem Kontrol. Yogyakarta: Graha Ilmu.

8. Ali, M. (2013). Konsep Dasar Sistem Kontrol. Yogyakarta: UNY.

9. Setiawan, I. (2006). Programmable Logic Controller dan Teknik Perancangan Sistem Kontrol. 
10. Carrillo-Bucio, J. L., Tena-Garcia, J. R., Armenta-Garcia, E. P., Hernandez-Silva, O., Cabañas-Moreno, J. G., \& SuárezAlcántara, K. (2018). Low-cost Sievertstype apparatus for the study of hydriding/dehydriding reactions. HardwareX, 4, e00036.

11. Bolton, W. (2004). Sistem Instrumentasi dan Sistem Kontrol (Judul asli: Instrumentation and Control Systems). 